\title{
Eski Uygur Budist Metinlerine Göre İnsan Embriyosu
}

\author{
Jens WILKENS ${ }^{1}$ \\ Çev. Muammer ŞEHITOĞLU²
}

Özet

Eski Uygur Türkçesi Dönemi Türkçenin tarihsel gelişimi ve değişimi içerisinde yazı dili boyutunda kültürel kavram, terim ve sözcük alışverişinin yoğun olduğu bir dönemdir. Özellikle Budizm'in etkili ve yaygın olduğu dönemde yazılan din temalı, konulu eserlerin Kağan ve kumandanlar tarafından Türkçeye tercüme ettirilmesi ile din terminolojisine ait pek çok sözcük, kavram ve terim Türkçeye geçmiştir. Türkçeye geçen bu terim, kavram ve sözcükler; Sosyal bilimlerin kapsam alanındaki disiplinlerin (din, edebiyat, siyaset vb.) olduğu gibi fen bilimlerine ait disiplinlerle de ilişkili olmuştur. Kurulan disiplinler arası bağ sayesinde Budizm'deki doğum ve ölüm inancının sadece mistik boyutta olmadığı; biyolojik boyutta da, yazı dilinde kaleme alınan eserlerde oluşan biyolojik terminolojinin de oluştuğu görülür. Dönemin metinlerinin dil özellikleri, dilin kavram ve terimleri ifade etme yeteneği de yapılan diller arası tercümeler aracılığıyla ortaya çıkmıştır. Jens Wilkens'in yapmış olduğu araştırma da bu açıdan değerli ve dikkat çekicidir. Çalışmada, J.Wilkens'in Eski Uygur Budist Metinlerine Göre İnsan Embriyosu adlı makalesi Türkçeye aktarılmış ve araştırmacıların dikkatine sunulmuştur.
Anahtar Kelimeler

J. Wilkens

Eski Uygur Türkçesi

Budizm

Makale Hakkında

Geliş Tarihi: 07.01.2020

Kabul Tarihi: 25.12.2020

Doi: $10.18026 /$ cbayarsos.671576

\section{Human Embryology According To An Old Uighur Buddhist Text}

\begin{abstract}
The Period of Old Uighur Turkish It is a period in which cultural concepts, terms and words are exchanged in written language dimension within the historical development and change of Turkish. Especially in the period when Buddhism was effective and widespread, many of the words, concepts and terms related to religious terminology have been translated into Turkish by translating the themed and themed works into Turkish by Kagan and the commanders. These terms, concepts and words that are translated into Turkish; It is related to the disciplines of social sciences (religion, literature, politics, etc.) as well as to the disciplines of science. Thanks to the interdisciplinary link, the belief that birth and death in Buddhism is not only mystical; In the biological dimension, it is seen that the biological terminology formed in the works written in the written language also occurs. The language features of the texts of the period, the ability of the language to express concepts and terms have emerged through the interlingual translations. Jens Wilkens' research is also valuable and remarkable in this respect. In this study, J. Wilkens' Human Embryos According to Old Uighur Buddhist Texts was translated into Turkish and presented to the attention of researchers.
\end{abstract}

Keywords

J. Wilkens

Old Uighur Turkish

Buddhism

About Article

Received:07.01.2020

Accepted: 25.12.2020

Doi: 10.18026/cbayarsos.671576 


\section{Özet}

Daśakarmapathāvadānamālā (On Eylem İlkesi İle İlgili Efsanelerin Derlemi); Eski Uygurca üzerine yüz yıl önce başlamış olan akademik çalışmalardan bu yana birçok çeşitli hikâyeyi bünyesinde barındıran geniş bir hikâye koleksiyonudur. Geçmişte tespit edilememiş hikâyelerin, günümüzde yapılan düzenleme çalışmaları sayesinde Budist Hikâyecilik Geleneği'ne ait olduğu görülebilecektir. Eski Uygurca bu hikâye koleksiyonu, hikâyecilik bakımından ilgi çekici materyaller içerir. Bunlar, Budizm'e Ait Ansiklopedik Bilgi terimi ile karşılanabilecek; "Budist arzuların uzun bir açıklaması veya ölüm belirtilerinin yavaşlaması, sönmesi" gibi konuları içeren materyallerdir. $\mathrm{Bu}$ materyallerden biri de anne kanındaki embriyonun gelişimi ile ilgilidir. Bu eser, eski Uygur Edebiyatında yer alan "embriyolojik yaşam" a dair en ayrıntılı açıklamaları içermektedir:

"Anne karnma girdikten sonra,

Aşır derecede pis kokulu, temiz olmayan maddelerle dolu,

Oldukça dar ve tamamı ile karanlık,

Tipkı bir cehennem gibi,

Aşırı derecede pis kokulu, temiz olmayan maddelerle dolu,

Oldukça dar ve tamamı ile karanlık-

Bir topun içinde ezilir

Ve büyük bir actya dayanır."

(Candragomin, Śisyalekha, stanza 19, tarnsl. Michael Hahn) 


\section{Giriş}

Kısa adı DKPAM olan eser; oldukça karmaşık, hacimli, on ayrı bölümden oluşan Eski Uygurca Budist hikâyeleri içeren koleksiyondur. Onlar arasında çok iyi bilinen birçok avadānaları ve genel hikâye içinde saklı birçok çeşitli hikâyeyi barındırır. Genel hikâye, öğretmen ve öğrencisi arasındaki konuşmaları içeren ilgi çekici konuları kapsar. En keskin biçimiyle; anlatılamayan, açıklanamayan metin bölümleri; özellikle de öldürme suçuna ayrılan birinci bölümdür. Oldukça dogmatik ve Budist Ansiklopedik Bilgi olarak adlandıracağım alanı ilgilendirmektedir. DKPAM'daki en uzun konuyu içeren bölüm; sekiz ana cehennemi ve orada yeniden doğmuş sefil varlıkları bekleyen acıların açıklandığı bölümdür. Bu bölümde, açıkça, çeşitli cehennem varlıklarının hayatına dair eleştirel başka bir ansiklopedik bilgi elde edilir. Burada, ölüm belirtilerini en ince ayrıntıları ile açıklayan öğretmenin ifadeleri bulunur.

\section{Uygur Budizmi'nde İnsan Embriyosuna Dair Yeni Kanitlar}

Makalede anne karnındaki embriyonun gelişimi ve orada çektiği acıyı ifade eden ilk bölümden metin içindeki başka bir bölüme geçilir. Ne yazık ki; bu açıklamaların yapıldığ fragman kısmen parçalanmıştır. Fakat yine de bu fragman, embriyolojik yaşam hakkında değerli bilgileri ve Fetüs'ün gelişiminin farklı aşamalarını ele alan bilgiler içermektedir. Benzer açıklamalar, Hint Tıp Araştırmaları ve Budist Edebiyatındaki çalışmalarda da bulunur.

Bu fragman, Berlin Turfan Koleksiyonu'ndaki Mainz 766 nolu belgede yer almaktadır. Bu belge, 3. Turfan Araştırmaları seferi sırasında bulunmuş veya edinilmiştir. (bkz. Kazı kodu T III 84-8). Bu konuyla ilgili fragmana dair ilk açılama Gerhard Ehlers Katalogu'nda bulunmaktadır. $\mathrm{O}$, belgenin bir nüshasını korur ve onun içeriğine dair açılamaları da doğru bir biçimde açılarii. Ayrıca bu fragmanı düzenleyen ve Türkçeye çeviren Murat Elmalı'nın çalışması da tatmin edici değildir.iii

İlgili bölümü, 18. satırdan başlayarak iki küçük parçayla (U $1648+$ m. 87) da destekleyerek bir inceleme yolu izlendi. Belge şu açıklama ile başlar: " yeryüzündeki kum taneleri kadar, 3 olumsuz durum (Skt. durgati) da doğan birçok canlı vardır. Onlar, doğar doğmaz acı çekmeye başlar." Sonra da metin, embriyolojik yaşamın açılaması ile devam eder. Bir insan olarak yeniden doğuş, varolan olumlu durum ( Skt. sugati) lar arasında sayılır. "Yine de herkes gebe kaldıktan hemen sonra başlayan şiddetli acılara katlanmak zorundadır." denilir. Rahmin içindeki yaşamın betimlenmesinden sonra öğretmen/hoca, bu konuyu kapatır ve hikâyenin genel anlatım çerçevesine döner. Öğrenci inançla hemhal olmuş ve Samsara'nın günahkârlığını gözünde canlandırmıştır. $\mathrm{O}$, bir insan vücudunu meydana getirmenin son derece zor olduğunu ifade eder. Ve buna rağmen de birçok insanın yine canlıları öldürme günahını işlemeye devam ettiğinden bahseder. Öğretmen, öğrencisinin bu düşüncelerini onaylayarak ona şu soruyu sorar: "Ölüm döşeğinde yatan bir kişinin korkuları tam olarak nedir?"

Jean Peter Laut, Maitrisimit'de tasvir edildiği gibi, çeşitli tedavi yöntemlerinde Eski Uygur Embriyonik Terminolojisine dair bilgilerimizin oldukça sınırlı olduğunu ortaya koymuştur.iv DKPAM'daki metinler parçalı, parçalanmış ve tahrip olmuş olmasına rağmen; insan embriyolojisi hakkında önemli materyaller, bilgiler içermektedir. Bu tür bir bilginin neden bir anlatı bağlamında ele alındığı ise bir problemdir. Her şeyden önce; şüphe yok ki, Samsara'yı anlamak ve ondan kurtulmaya çalışmak Budist embriyoloji ile yakından ilişkilidir. Diğer 
yönden ise; Budist embriyolojinin esas karakteri dindir.v Ayrıca bağımlılık kökenli öğreti ( Skt. pratītyasamutpāda) ile olan bağlantıyı da belirtmeliyiz. Bu noktada, anne karnına girişteki bilinc (Skt. vjūāna) in rolü önemlidir. ${ }^{\mathrm{vi}}$ Maitrisimit'in 15. bölümünde, anne ve babanın üreme mekanizmalarına giren bilincin gelişerek "nama-rupa kompleksi" ( Eski Uygurca: at ö $\eta$ ) ne dönüştüğü belirtilir.

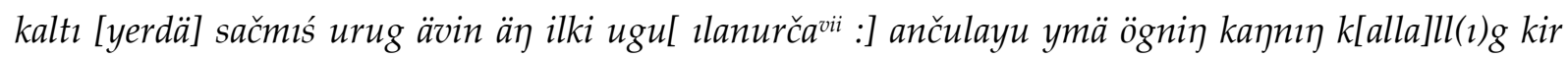

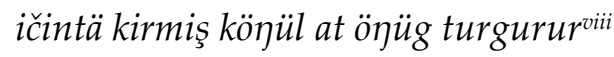

"Tıpkı toprağa atılan ilk tohum gibi anne ve babanın üreme mekanizmasına giren bilinç de orada bir "kimlik" oluşturur." Kaşmirli ünlü yazar Kşemendara tarafından yazılan hikâye koleksiyonu Bodhisattvāvadānakalpalatā olarak adlandırılır. Buradaki avadana ise, Garbhāvakrāntyavadāna yani "embriyonun oluşumu ilgili efsane" olarak bilinir. Onun giriş bölümünde embriyonun gelişmesi de yer alır. ${ }^{\text {x }}$ Onun editörünün de belirttiği gibi aslında bir efsane değil oldukça kısa bir tezdir. ${ }^{\times}$Bu avadāna'nın ilk bölümünde embriyonik durum, bağımlı köken zincirinin "temas" (Skt. sparśa) etkeni ile ilişkilendirilir. ${ }^{x i}$

2008 yılında basılmış Tibet Budizm Geleneği üzerine yazılmış olan bir kitapta embriyoloji hakkında bilgilerin yanı sıra hamilelikte uygulanacak meditasyon yöntemlerinin önemi ile ilgili de bilgi verilir.xii Buna benzer bir tutum Hindu Geleneğine ait Garuḍapurānáda da görülür.xiii Burada, doğum ve embriyolojik gelişim hakkındaki düşünceler ile sindirim, doğum, hastalık, yaşlılık, ölüm ve yaşam geçiciliği gibi diğer temalar arasında bir ilişki olduğu da belirtilir. ${ }^{\text {xiv }}$

Eski Uygur metinlerinde görüldüğü gibi her insanın yaşaması gereken acılar rahimde/anne karnında başlar. ${ }^{x v}$ Ve meditasyon yapan Budist bir rahip veya rahibe, insan vücudu hakkında kapsamlı bilgi sahibi olmak için öncelikle vücudunu uygun bir şekilde kontrol etmeyi başarmalıdır. ${ }^{\text {vi }}$ Birçok kez, DKPAM'ın eğitim için ve özellikle de sıradan insanların eğitimi için tasarlandığ 1 iddia edilmişti. Fakat metinden anlaşıldığı kadarıyla, o Budist Ansiklopedik Bilgi içermesi nedeniyle daha çok rahip ve rahibelere yönelik bir amaçla hazırlanmıştı. Bununla birlikte, eserin, sıradan insanlar arasında da "Budist Öğreti"lerin yaygınlaştırılması için kullanıldığ 1 yadsınamaz. ${ }^{\text {xvii }}$

\section{Embriyolojik Gelişmenin Aşamaları}

Her ne kadar belgenin metninde insan embriyosunun gelişiminde farklı aşamalar tespit edilmiş olsa da;

\section{Ilk Aşama:}

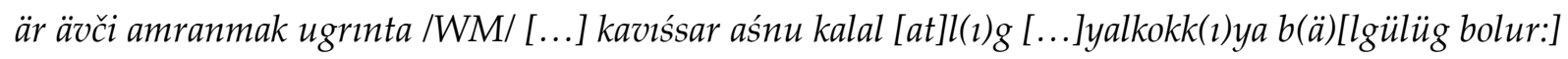
(Mainz $766 / r / 11-13 /$ ).

"Bir erkek ve bir kadın şehvetle cinsel ilişkiye girdiğinde ilk olarak "kalala" denilen jöle benzeri küçük kaygan bir madde ortaya çıar." 
Hint Tıp Araştırmalarında sperm (meni) (Skt. śukra)xviii, kadının kanı (Skt. śọita) ${ }^{\text {xix }}$ ve insan embriyosu (Skt. garbha) ${ }^{\mathrm{x}}$ nun oluşumuna neden olan geçişli faktör (Skt. jīva) e sahip özel bir birleşim olarak tanımlanır. Suśrutasaṃhitā'da, kadın üreme sıvısı ile sperm arasında karşılıklı karmaşık bir etkileşimi oluşturan yani ilişki sırasında geçen ve gebeliğe elverişli diğer bileşenlerin oluşturduğu varlık olarak açıklanır. ${ }^{\text {xi }}$

İlk aşama, Eski Uygur metinlerinde kalalxxii olarak adlandırılan embriyonun oluşumudur. Sözcük, Toharca aracılığıyla (ef. Tocharian B kaläl, Adams 2013, p. 156) Sanskritçeye kalala $a^{x x i i i}$ olarak geçmiştir. Toharcanın A lehçesinde bu terim yoktur. Toharcanın B lehçesinin sözlüğünü hazırlayan Adams tarafından kavram ile ilgili olarak şu etimoloji önerisi ileri sürülmüştür: "Sözcüğün käl- "dayanmak, bel bağlamak” kökünden geldiği kabul edilemez; çünkü sözcüğün Sanskritçeden ödünç alındığ 1 açıktır". xxiv

Budist metinlerin aksine, Hint Tıp Geleneği'nde embriyo, hamileliğin ilk ayında "kalala" olarak adlandırılır. ${ }^{x \times v}$ Onun bileşenleri, Carakasamhitā 'da jöle benzeri bir karışım olarak

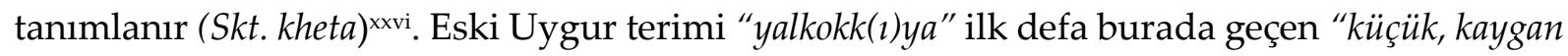
jöle benzeri bir madde" olarak tercüme edildi. O, Türk dilindeki "yalkuk" sözcüğü ile ilişkilendirildi. Sözcük, Derleme Sözlüğü'nde "jelly-fish" "denizanası" anlamındadır.xxvii

DKPAM'daki aşamaların açıkladığı üzere; eski Uygur metnine göre "kalala" nın sadece yedi günde oluştuğu belirtilir. ${ }^{x x v i i i}$ İnsan embriyosunun gelişiminin bu ilk aşaması, yani kalala'nın, Pali ve Sanskrit geleneğinde de Budist gelenekle benzer biçimde, yedi günlük sürede oluştuğu doğrulanır.

\section{İkinci Aşama}

anta basa yeti [küntä ken] ol ok yalkokk(1)ya //[...] barır: (Mainz 766 /r/14-16/).

"Sonradan (ondan sonra) yedi gün aynı jöle benzeri madde gider."

İkinci aşama için özel embriyonik terim, bizim eski Uygur metnimizde eksik olduğundan dolayı bu aşama genel anlamda "arbuda" veya Hint Tibbında kullanılan "badbuda" terimi ile karşılanır. xxix Carakasaṃhitä'da "katı kütle" (Skt. ghana) olarak geçer ve hamileliğin ikinci ayında geliştiği belirtilir. O embriyo eğer erkek ise küre (Skt. piṇda) şeklinde; kadın ise oval (Skt. peśi) biçimdedir. En sonunda, eğer onun cinsiyeti belli değilse (Skt. napumssaka) ${ }^{\mathrm{xx}}$ bir yarımküre (Skt. arbuda) ye benzer. Bu aşama Pali Geleneği'nde "abbuda" olarak bilinir. Genellikle yedi günlük bir embriyo olduğu belirtilir.xxi Benzer şekilde Budist ve Sanskrit metinlerde de "arbuda" olarak adlandırılan bu aşamanın yedi günlük olduğu vurgulanır.

\section{Üçüncü Aşama}

yänä ök küntä ol kan ät tanču bolur: : anta basa ol ät tančuta kol but b(ä)lgüläri sögülk(i) yälär: arıgsız akguluk tälökk(i) yälär b(ä)lgülüg bolur.. (Mainz 766 /r/ 16-21/).

"Yine yedi gün sonra kan ve etten oluşan bir parça haline gelir. Ve daha sonra bu et parçasında kollar ve bacaklar ayırt edilir. Bunların yanı sıra bu et parçasının içinde daha sonra ürettiklerini dışarı akıtması ve dışkıların atılması için küçük delikler oluşur."

"kan et karışımı" ya da "et parçası" kavramı embriyonik gelişmenin üçüncü aşamasını karşılar. "Et parçası"xxxii kavramı Sanskritçede pesī olarak adlandırılır. Pali Geleneğinde de aynı adla 
adlandırılarak ikinci aşamadan sonraki yedi günlük süreç olarak anılır ${ }^{x x x i i i}$. Bu bağlamda Budist kaynakların tamamında ve bizim eski Uygur metinlerinde böyle bir istisna durum yoktur. Eski Uygur metnine göre; ilk olarak onun organlarının gelişiminin başladığına dikkat çekilir. Carakasaṃhitā ve Suśrutasaṃhitā' ya göre ise; onlar 3. ayda gelişmeye başlar. ${ }^{\text {xxxiv }}$

Pāli metinlerinde bu beş organdan; baş, el ve ayakların yalnızca "pasākh"̄" olarak adlandırılan rahmin son aşamasında geliştiği dile getirilir. Budist Sanskrit Geleneği de bu bilgiyi doğrular. Öyle ki "pasākh"̄" terimi de buna karşılık olarak bulunmuştur.

DKPAM'da yer alan sögülk(i) yälär kavramının kol but b(ä)lgül(ä)ri kavramına karşllık gelip gelmediği merak konusudur. Bir yandan Suśrutasaṃhitā'da bu beş (çıkıntılı) organdan bahsedilirken; diğer yandan anga ve pratyānga arasında bir farklılık bulunduğunu tespit edilidi. (Skt. àngapratyāngavibhāgaśca sūkșmo bhavati)..xxv Belki de sögülk (i) yälär hem añga'y1 hem de pratyāng $a^{\prime} \mathbf{y}$ karşılamaktadır.

Şimdi en ayrıntılı ve en uzun süreyi kapsayan dördüncü aşamaya geçelir:

\section{Dördüncü Aşama}

“ol känč karınta ornamıśta anasınıๆ aylıkı üzä ätöz igidür: yig aś turgu biśı aś turgu bo iki oron ikin ara ol känčni门 turgu ornagı ol: : anası nägü yesär [i]çsär ol tatıg kindikintin sıza kirip [anı] üzä ol ogulk(i)ya //[...] tutar: :"

"Embriyo annesinin karnına yerleştikten sonra, annenin "aylık periodu"xxxvi aracılığ1 ile kendisini korur. (aşağıdaki şekilde olduğu gibi beslenir): embriyo hem çiğ(sindirilmemiş) (Skt.

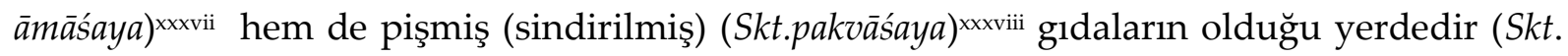
garbhāśaya)xxxix. Annesi ne yer ne içerse o küçük çocuk da kendi göbek kordonu aracılı̆̆ ile onu (Skt. rasa) ${ }^{x l}$ yer ve içer."

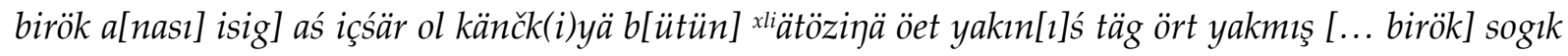
suw ičsär: buzl[ug ...] ičintä kalamıś täg ol [ogulk(i)ya] birök anası töpön y[atsar ulug] tag basmıs täg ämgänür [...] kärigdä [käril]m[i] śxlii tägxliii [...] / R[...]: (Mainz 766/r/21/-/ v/7/).

"Annesi sıcak çorba içerse, bir alev o ceninin bütün vücudunu yakmış gibi ateşlendirirxliv. Soğuk su içerse bu embriyo kendini bir buzda yüzüyormuş gibi hisseder. Eğer annesi başının üstüne yatarsa embriyo üzerine büyük bir dağın ağırlığı çökmüş gibi hisseder. Sanki bir rafta dik duruyormuş gibi olur."

Gelişimin bu dördüncü aşaması; Budist, Sanskrit ve Pali Edebiyatında üçüncü aşamadan sonraki yedi günlük süreci kapsayan dönem olarak "ghana" terimi ile karşılanır.xlv Fakat DKPAM'ın sadece oldukça kısa olan bu aşamaya değinmemiş olması muhtemel değildir. Öyle görünüyor ki; onun anne karnındayken çocuğun dayanmak zorunda olduğu çeşitli acılara atıfta bulunan genel bir duruma karşılık geldiği belirtilmektedir.

Eski Uygur metninde fetüs ile onun annesi arasında yakın bir ilişki olduğuna dikkat çekiliyor. Hint Tıp Literatüründe; bu fizyolojik bağlantı, annenin çocukla aynı gereksinimlere sahip olduğunu belirten bir ilişki bağı olarak sık sık vurgulanır. Çocuğa zarar vermekten kaçınmak için hamile kadının yoğun istekleri (Skt. dohada) nin karşılanmasının çok önemli olduğu dile getirilir. ${ }^{x l v i}$ Embriyonun beslenmesi Suśrutasaṃhitā'da $(3,3,31)$ şu şekilde tanımlanır: Çocuk göbek bağı aracılığı ile annesinin "rasa" denilen taşıma kanalıyla ona bağlanır. (Skt. mātastu khalu rasavahāyām nā ḍyām garbhanābhināḍ̄ pratibadha) ${ }^{x l v i i}$ Bu kanal, anne ve embriyo bağlantısını 
sağlayan āpyāyan̄ xlviiiterimi olarak da bilinir. Sanskritçedeki rasa kavramına karşılık olarak eski Uygur metininde tatıg kavramı kullanılır. Dieter Maue da rasa ${ }^{x l i x}$ 'nın “öz, esas” olarak tercüme edilebileceğini belirtir (Maue, 2008, s. 137).

İlgi çekici bir şekilde; DKPAM, üç önemli Hint Tıbbı kaynağına göre; kadın anotomisinin bir parçası olan üç hazneden bahsetmektedir. $\mathrm{Bu}$ kaynaklar: Suśrutasaṃhitā', Aștāngahrdayasaṃhitā ve Kāśyapasaṃhitā'dır. Bir erkek bu üç hazneden yoksundur. Üç metinde bazı farklılıklarla birlikte kadınlar için sekiz değişik hazneden bahseder. Suśrutasaṃhitā' daki adları şöyledir:1
1) vāta haznesi
2) pitta haznesi
3) kapha haznesi
4) kan haznesi
5) çiğ yiyecek haznesi (āmāśaya)
6) pişmiş yiyecek haznesi (pakvāśaya)
7) idrar torbası haznesi (mūtrāśaya)
8) rahim haznesi ( garbhāśaya)

Karşılılıkları şu tablodan görülebilir:

\begin{tabular}{|c|c|c|}
\hline Hazneler & DKPAM & Sanskrit Tıp Terimleri \\
\hline $\begin{array}{l}\text { Ham (sindirilmemiş) yiyecek } \\
\text { haznesi }\end{array}$ & yig aś turgu & $\bar{a} m a \bar{s} s a y a$ \\
\hline $\begin{array}{l}\text { Pişmiş (sindirilmiş) yiyecek } \\
\text { haznesi }\end{array}$ & biślg aś turgu & pakvāśaya \\
\hline $\begin{array}{l}\text { Embriyo ya da fetüs (rahim vb.) } \\
\text { haznesi }\end{array}$ & känčniך turgu ornagı & garbhāśayali \\
\hline
\end{tabular}

Suśrutasaṃhitā' daki Śarīrasthāna'da biraz değişik, sapma gösteren bir tanım elde edildi. Eserde, embriyonun haznesinin pişmiş veya çiğ yiyecek haznesi ile safra haznesinin arasına yerleştiğ $i$ söylenir. lii Aștāngahrdayasaṃhitā' da da bu bilgi doğrulanır.

Eski Uygur metninde anlatılan bu acı çekmeler / sıkıntılar, Pali metni Visuddhimagga'da da benzer biçimde yer alır. Şu dipnotta da belirtilir:

“O, annesi tökezlediğinde, oturduğunda veya kalktığında, döndü̈̆̈̈̈nde; sarhoş bir kişinin eline düşen veya yılanın eline yeni düşmüş bir çocuk gibi yukarı aşağı sürüklenerek, sallanarak aşırı bir acı çeker. Yine annesi soğuk su içtiğinde; o, soğuk cehennemde bulunuyormuş gibi olur. Annesi sicak pirinç yağı veya pirinç vb şeyler yutarken çocuk sert bir yağmurda teni delinecekmiş gibi acı hisseder. Yine annesi Tuzlu veya asidik bir şey yuttuğunda çocuk; kendini sanki alkolik asitlenmeyle temizlenmeye çalışılan bir madde gibi hisseder. Bunlar gebelik kökenli acılardır." liii 


\section{Beşinci Aşama ${ }^{\text {liv }}$}

tokuz ay on küni tükäsär tugguluk üdi kirtökdä kılınclıg yel [üz] ä [tug] um kapıgına töpön käm [iśilip ämgäkli]g tilgän ara [yančllmiś] täg ämgäk [ämgänür:]"v (Mainz 766/v/7-13/).

“Dokuz ay on gün tamamlandıktan sonra doğum zamanı geldiğinde doğum öncesi (doğum kanalına) "karma rüzgarı"lvi (doğum sancısı) başlar. Burada acı çekme deneyimleri (vücudun) tekerleğin altında ezilirken çektiği acı gibidir."

\section{Sonuç}

Anne karnındaki embriyonun gelişiminin beş aşamada gerçekleşebileceğini tespit edilmiştir. Fakat onlar sadece ilk üç aşamayı diğer Budist eserlerde yer alan açıklamalarla ifade ederler. Üçüncü aşama burada ifade edilmiş olsa bile; aşamada kollar ve bacaklar zaten gelişmeye başlamaktadır. Genellikle ilk dört aşama şu şekilde adlandırılır: kalala, arbuda, peśī ve ghana. ${ }^{\text {lvii }}$ Çocuğun doğumuna kadar geçen ve gebeliğin beşinci haftasında başlayan praśākhā olarak adlandırılmış son aşama haricinde her bir aşama yedi günlük süreci kapsar. ${ }^{\text {lviii }}$

Embriyonun karşılığı olarak yabancı dilden alınan "kalal" kavramını bulundu. Onun, küçük kaygan jöle benzeri bir madde olarak yalkokk(i)ya kavramı ile karşılandığını tespit edildi. Üçüncü aşamayı karşılayan kavramların eski Uygurcadan tercüme edilen kan ät tanču ya da ät tanču olarak belirlendiğini ama ikinci aşamanın herhangi bir kavramla karşılanmadığ1 belirlendi. Embriyo veya fetüs için kullanılan genel kavramlar dördüncü aşama için de kullanılır. Bunlar; känčlix, ogulk(i)ya ve känčk(i)yä'lx dir. Maitrisimit'de embriyo veya fetüs için kullanılan birkaç kavram tespit edildi. Bunlar; karıntakı ogul, "fetüs in the womb"; yig ogul, "

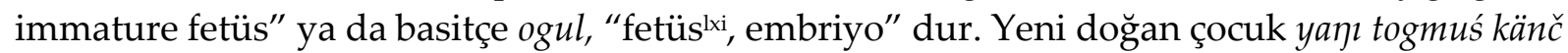
oglan ${ }^{l x i i}$ ya da yajı tuğmuş oglan olarak adlandırılır. Burada, ogul ile oglan lxiii arasındaki farklılık ise dikkat çekicidir. 


\section{Kisaltmalar}

BT XIII bk. Zieme 1985

DKPAM Daśakamapathāvadānamālā

DS bk. Aksoy et al. 2009.

DTTA bk. Carling 2009

Mainz Berlin Koleksiyonu'ndaki fragmanları gösterir. (Mainz Koleksiyonu).

MaitrH XV Maitrisimit'in Hami Versiyonu'nun 15. Bölümü.

MaitrH XX Maitrisimit'in Hami Versiyonu'nun 20. Bölümü.

$/ \mathrm{r} /$ recto

Skt. Sanskrit

SWTF Turfan Araştırmalarındaki Budist Metinlerin Sanskritçe Sözlüğü. E.Waldschmidt tarafından başlatılan yayınlar; Heinz Bechert tarafından yayımlanan örnek versiyonlar ile devam eder ve Georg von Simson, Michael Schmidt tarafından da düzenlenerek yayımlanır. Göttingen 1973, s.99.

T137 Bao Tai Jing (Garbhāvakrāntinirdeśa) İn. Taisho Shinshu Daizokyo No. 137, Vol. XI.

U Berlin Turfan Koleksiyonu Fragmanlarını gösterir.

/v/ verso

\section{Kaynakça}

Adams, Q.D. (2013). Toharca B (Lehçesi) Sözlüğü. Genişletilmiş ve düzenlenmiş. Vol. I-II. Amsterdam, New York.

Agostini, G. (2004). Öldürülmekten Farklı Olarak Doğum Esnasında veya Doğmadan Önceki Ölüm Üzerine Budist Kaynaklar. Journal of The International Association of Buddhist Studies, 27/1, s. 63-69.

Aksoy, A. Ö. (2009). Türkiye'de Halk Ağzından Derleme Sözlüğ̈̈, Ankara, Vol. I-IV.

Boisvert, M. (2000). Palicede Rahim İçindeki Yaşam ve Gebe Kalma, Canon Studies İn Religion, 29/3, s.301-311.

Carling, G. (2009). Toharca A (Lehçesi) Sözcük Hazinesi ve Sözlüğü, Vol. 1; A-J. W.Winter, G. J. Pinault ve g. Carling tarafından birleştirilip tamamlanmıştır. Wiesbaden.

Dossi, B. (1998). Tohumlar, Göller, Kan, Eski Hindistan Vatandaşlı̆̆̆, München, (Ganesha 11).

Ehlers, G. (1987). Eski Türkçe El Yazmaları, Böl.2: Das Goldglanzsutra und der Buddhistiche Legendenzyklus DKPAM. Depositium der Preußischen Akademie der Wissenschaften( Staatbibliotek Preußischer Kulturbesitz, Berlin). Stuttgart (Verzeichnis der Orientalischen Handschriften in Deutschland XIII, 10).

Elmalı, M. (ed. Transl.) (2009). DKPAM (Daśakamapathāvadānamālā), Giriş, Metin, Çeviri, Notlar, Dizin, Tipkıbasım. Doktora Tezi. T.C. Marmara Üniversitesi Türkiyat Araştırmaları Enstitü, Türk Dili ve Edebiyatı Ana Bilim Dalı, Türk Dili Bilim Dalı, İstanbul. 
Elmalı, M. (2012). Eski Uygurca Yalgukk(i)ya Kelimesine Etimolojik Bir Yaklaşım. Turkish Studies, $7 / 2$, s. 443-460.

Florida, R.E. (1991). Çocuk Aldırma Üzerine Budist Yaklaşımlar, Asian Philosophy, 1/1, s. 39-50.

Garrett, F. [Mary] (2008). Din, Tip ve Tibet'te İnsan Embriyosu, London, [et. al.], (Routledge Critical Studies in Buddhism).

Geng. S.; Klimkeit, J.H.; Laut, P.J. (1993). Eşsiz Budalığın Kazanılması, Das. 15. Kapitel der HamiHandschrift der Maitrisimit, Altroientalische Forschungen, 20, s. 182-234+13.

Hahn, M. (1997). Kṣemendras (Garbhāvakrāntyavadāna) (Sanskrittexte aus dem Tibetischen Tanjur II.), Journal of Europen Ayurvedic Society 5, s. 82-112.

Hertel, J. (1914). Das Pañcatantra: Seine Geschichte und seine Verbreitung, Leipzig, Berlin.

Huebotter[Franz] (Transl.) (1932). Embriyoloji ve Onun Anlayışı Üzerine Kutsal Kitaplar (Sutra), Tokyo, (Almanya'nın Doğu Asya ve Etnoloji Derneği İletişimi XXVI, Böl. C).

Kirfel, W. (1954). Garudapurānas. İn. Schubert, Johannes, Schneider, Ulrich (eds.) Asiatica, Friedrich Weller için Hatıra, zum. 65, Onun Arkadaşları, Kolejdekiler ve Öğrenciler tarafindan hazırlanmış 65. doğum günü Yılı Adına, Leipzig, s.333-356.

Laut, J.P. (1995). Eski Uygurlarda Çocuk Aldırma Uygulamalarını Tanımlamak, In: ErdalMarcel, Tezcan-Semih (eds.) Beläk Bitig: Gerard Doerfer İçin Dil Çalışmaları zum. 75. Doğum Günü Yılı Adına, Weisbaden, (Turkologica 23), s.109-120.

Lenz, T. (2003). İlk Doğum Hikâyelerinin Bir Koleksiyonu ve Gāndhāri Dharmapada'nın Yeni Bir Verisyonu, British Library Kharoșțhī Fragmanları 16+25 Seattle/ London (Gandhāran Buddhist Text 3).

Maue, D. (2008)..Vāgbhața's Așțāngahrdayasamhițā, Asian Medicine 4, s.113-173.

Major, M. (2007).Boddhisattvāvadāna- Kalpalatä (10) Kṣemendras'ın Tibetçe Düzyazı Versiyonu. In: Klaus, Konrad, Hartmann, Jens Uwe (eds.), Indica et Tibetica: Michael Hahn'ın 65. Doğum Günü Yılı Adına Öğrencileri ve Arkadaşlar tarafından haz., Wien (Wiener Studien zur Tibetologie und Buddhistmuskunde 66), s. 341-350.

Meulenbeld, G[errit] J. (1999-2002). Hindistan Tıp Literatürü'nün Tarihi, Vol.IA-III, Groningen.

Müller, Reinhold, F.G. (1955). Eski Hint'te Embriyoloji, Leipzig, (Nova Acta Leopoldina Nue Folge 115).

Nāṇamoli, H. (2010). Arıtma Yolu, Visuddimagga,Kandy.

Powers, J. (2009). Bir Adamın Boğazı: Hindistan Budizm'inde Vücud, Cinsiyet ve Erkeklik Organı, Cambridge mass / Londra.

Reck, C. (2005). İnsanın Var Oluş Çilesi. Kelile ve Dimne'deki Burzōy'un Önsöz Metinine karşılık Olarak Soğdca Bir Fragman. In: Tongerloo, Aloïs van Cirillo, Luigi (eds.), II Manicheismo, Nuove Prospettive della Richerca (sic). Dipartimento di Studi Asiatici Univerista degli Studi di Napoli "L" Orientale Napoli, 2-8 Settembre 2001. Turnhout (Manichean Studies V), s. 331-341.

Röhborn, K. ; Rona-Tas, A. (ed. Transl.) (2005). Orta Asya Budizm'in Geç Formları, Eski Uygurca Sitātapatrādhāraṇi, Düzenleme, Tercüme ve Yorumlama, Göttingen, (Nachrichten der Akademie der Wissenschaften zu Göttingen, Philolosich-historische Klasse, 2005, Nr. 3). 
Schlieter, J. (2005). Budist İnsan Klonlanması Üzerine Bazı Düşünceler. In: Roetz, Heiner (ed.), Cross-Cultural Issues in Biothics- The Example of Human Cloning, Amsterdam,s. 179-202.

Sharma, P. V. (eds. Transl.) (1999-2001). Suśruta- Saṃhitā, İngilizce Metin Çevirisi İle Birlikte Dalyaṇa'nın Yorumları ve Eleştirel Notları, Vol. I-III. Varanasi, (Haridas Ayurveda Series 9), Suneson, Carl 1991, Eski Hindistan Embriyolojisi İle İlişkili Bazı Terimler Üzerine Düşünceler, Weiner Zeitschrift füt die Kunde Südasiens, XXXV, s. 109-121.

Tekin, Ş. (1980). Maitrisimit nom bitig. Vainhāṣika Okulu'na Ait Budist Bir Eserin Çevirisi, 1. Böl: Transliterasyon, Çeviri, Açıklamalar, 2. Böl: Analizle ve İndex, Berlin, (Berliner Turfantexte IX).

Tuguşeva, L. Y. (2008). Sutra Obściny belogo lotosa. Tjurkskaya versija, Faksimile rukopisi, Transkiripcija teksta, perevod s rannesrednevekovogo tjurkskogo jazyka, predislovie, primecanija, ukazatels'lov. Moskova, (Pamjatniki pis'mennosti vostaka CXXVII).

Zenker, J. T. (2009). Türkçe- Arapça- Farsça El Sözlüğ̈̈, Hildesheim/Zurich/New York, [1866].

Zieme, P. (eds. Transl.) (1985). Budist Uygurlarm Aliterasyonlu Mühürleri, Berlin, (Berliner Turfantexte XIII.)

Zieme, P. ; Kara, G. (eds.transl.) (1978). Bir Uygurca Ölü Defteri, Dunghuang (Bin Buda) British Museum'da El Yazması Koleksiyon'undaki Tibetçe'den Terücem Edilmiş Uygurca Nāropas Öğreti Kitabı,Or. 8212 (109), Budapeşte,(Bibliotica Orientalis Hungarica XXII).

1 University of Goettingen, member of faculty, Jens.Wilkens@ phil.uni-goettingen.de.

2 Dr., mshtg122@gmail.com., https://orcid.org/0000-0003-4471-3283.

\section{Açıklamalar}

i Deposititum Berlin-Brandenburgischen Akademie der Wissenshaften in der Staatsbibliothek zu Berlin Preussischer Kulturbesitz, Orientsbtcilung.

ii Ehlers, 1987, catalogue number 229 (facsimiles on plate 28).

iii Elmalı 2009, pp. 5-7 (lines 0131- 0194), Re-edited in Elmali 2012.

iv Laut 1995, p. 116. In footnote 19 o çoğunlukla popüler embriyoloji (volkstumliche Embryologie) nin söylediklerine atfen bunu belirtiyor.

v bkz.Garrett 2008, p. 19. Burada ilgi çekici olan insan klonlanması ve kök hücre araştırması üzerine çağdaş bir Budist söylem olmasıdır.

vi Florida 1991, p.41.

viiProf. Dr. Klaus Röhrborn'e (Göttingen) bu yeni restorasyon (belge okuma düzeltimi) a teşvik ettiği için teşekkür ederim.

viiiMaitrH XV folio 8 / v/ 20-24/ (ed. Geng/ Klimkeit/ Laut 1993, p. 194).

ixbkz 1997 yılında Hahn tarafından yorumuyla birlikte yapılan Sanskritçeden tercüme ve düzenleme. 2007 yılında Mejor tarafından Tibetçeden yapılan tercüme ve düzenleme versiyonu, s. 345-349.

xHahn 1997, pp. 83-84.

xiHahn 1997, pp. 86.

xiiGarrett 2008, p. 18.

xiiiKirfel 1954, p. 345.

xivPowers 2009, p.126. 
xvenzer bir açıklama Burzoes' in Kelile ve Dimne adlı eserinin ön sözünde yer alır. Christiane Reck tarafından 2005 yılında yayımlanmış olan bir Mainihaist eserle koşuttur. Onun ilgi çekici kılan DKPAM ve Burzoe ile karşılaştırıldığında Fetüsün ağrısı onlarla aynı düzlemde ele alınır. CF.Hertel 1914, p. 368. Anne karnındaki yaşam tipik bir Hint motifi işkencesi gibi gösterilir. Anne karnında olmak bir varlığın cehenneme düşmesi ile eş tutulur. CF. Dossi 1998, pp. 79-83 ve özellikle p. 82; “ Mit dem Aufkommen des Leben Leid -Dogmas tritt die Verteufelung des mutterlichen Schoßes ein. Eine, Verhöllung des Muttershoßes findet in den Texten statt, die den Embriyonalzustand vom Leben des Geborenen als eigene Existenzform abtrennen. CF. The verse by Candragomin which is quoted above as a motto.

xviEski Uygurca "Ölümün Kitabı"nda yer alan Dunghuang'daki Tantrik El Yazmaları olarak bilinen yazmalarda embriyonik gelişme ve embriyo kavramı ile birlikte uzun bir bölüm olarak ele alınır.

xviiBudist Edebiyatı Öykücülügü'nün vurguladığı sorun Timothy Lens tarafından ele alınmıştı. O, şöyle yazmıştı; "Yine de avadānaların ve pūrvayogaların özellikle öğretiyi yaygınlaştırmak ve bağış için kullanıldığı şüphelidir. Aslında rahiperin kendilerinin daha az ön plana çıktığı ya da avadana literatürüne hiç ilgi duymadıklarına dair herhangi bir kanıt yoktur. Aksine avadānaların, pūrvayogaların ve jatakaların öğrenilmesine ve öğretilmesine karar vermek için rahiplerin de bunun üzerine çalışmasının bir nedeni var."

xviiiCf. Dossi 1998, pp. 14sq. Hin Literatüründeki diğer terimler için örneğin; reats, bijja, toka, garbha, or turīpa bkz. Müller 1955, pp. 6-7 ve Dossi 1998, p. 21.

xixbkz. Dossi 1998, pp. 14 sq. Kadınlardaki etkin madde için ayrıca şu terimler kullanılır: ārsava, rakta rajas. Cf. Müller 1955, pp.14-21.

xxCarakasaṃhitā 4 Śarīrasthāna bölüm 4, verse 5 (cf. Meulendbeld 1999-2002, IA, P.41).

xxiMeulendbeld 1999-2002, IA, P. 246 ( 3 Śarīrasthāna, bölüm 3, verse 4).

xxiibkz. Laut 1995, diğer atıflar için dipnot 19. MaitrH. XV FOL. 8/v/20-24/ ayrıca dipnotlar da dâhil edilir. Orada sözcügün ekli biçimi k[ala]ll(1)g de yer alır.

xxiiiKirfel 1954, p.345. bkz. SWTF 9-15, ayrıca PP.34b-35a.

xxivSanskritçe terimin kökeni Suneson tarafından veriliyor. (1991, p.110 dipnot 7). O, makalesinde Hint embriyolojisini ele alırken, onu leke veya akışkan olan belirsiz sıvı olarak düşünmüştür. Vāgbhata's Aștāñgahrdayasaṃhitā'ya göre; (2,1, 37-42) muhtemelen o aşama kalala' dır. Diğer tıp metinlerindeki gibi yaklaşık bir aylık süreyi kapsar, ayrıca çocuğun erkek doğmasını sağlamak için pumsavana ritüelini gerçekleştirerek çocuğun cinsiyetine etki edilebileceği düşünülür. Bkz. Meulendbeld 1999-2002, IA, P. 410.

xxv Meulenbeld 1999-2002, IA, P.246.

xxvilbid, IA, P.41.

xxviiDS VI, p. 4149b (Düzköy) Elmalı farklı bir yorum getirmiştir. 2012.

xxviiiKalala üzerine $b k z$. Dossi 1998, pp.92sq.

xxixCf. Suneson 1991, p. 111. Vasubandhu'nun Abhidharmakośabhāaya eserinde "arbuda" olarak adlandılır. Bkz. Garrett 2008, p. 28 Arbuda üzerine bkz. SWTF 2, P. 149b. Embriyonik gelişmenin ikinci aşaması için diğer tanımlar bkz. Dossi 1998, p. 93.

xxxBu terim Suśrutasoṃhitā ve Carakasaṃhitā'da aynı biçimde yer alırken; Aṣtāngahrdayasaṃhitā' da klība şekilnde yer alır.

xxxiBoisvert 200, p. 307.

xxxii Suneson 1991, pp. 110sq. Bu terim, Vasubandhu tarafından da kullanılmıştır. O. Sonraki ki aşamayı ghana ve praśākhā olarak adlandırır. bkz. Garrett 2008, p. 28. peśí üzerine cf. SWTF 17, P. 152. Üçüncü aşamanın farklı tanımları için bkz. Dossi 1998, pp. 94sqq. 
xxxiiiBoisvert 2000, pp. 307sq.

xxxivGarrett 2008, pp. 20, Meulenbeld 1999, IA, PP. 41,246.

xxxvSharma 1999-2001, II, PP. 144.

xxxviBu ibarenin onayı eski Uygurcadaki aylık kavramıdır. Osmanlı Türkçesindeki anlamı ise; “ adet dönemi, aylık period" dur. bkz. Zenker 2009, p. 152a (les mentrues).

xxxviiBu terim Toharcanın A lehçesinde āmiśāg biçimindedir. bkz. DTTA 40a-b: “ sindirilmemiş yiyecek haznesi, mide"

xxxviiiSt. Petersburg koleksiyonundaki Abitaki yaprağının III 43a 9'uncu satırında yer alan kavram; Eski Uygurca aś bıśıg ve aś agılıkı kavramlarına karşılık gelmektedir (Tuguşeva 2008, p. 38).

xxxixEmbriyonun tanımı Maitrisimit'in Sangim versiyonunda da iki hazne arasına sıkışmış rahim olarak verilmiştir. (plate 198/r/22-24/, ed. Tekin 1980, 1, p. 248): [...] yalnok azunınta tugguluk tınl(1)glar ög karnı içintin yig as bısıg as ornı ikin ara sıkılıp [... ; [...] "insan olarak yeni doğmuş olan canlılar, pişmiş gıda haznesi ile çiğ gıda haznesi arasındaki anne karnının içinde sıkışıyorlar. [...]"

xlVeya "öz, esas" (bkz. altta).

xliYeniden okunuşu da belli değil.

xliiOkunuşu belli değil.

xliiiBu sözcük yoğun zarar görmüş.

xlivEmbriyonun yanma hissini yaşaması. bkz. Dossi 1998, pp. 87sqq.

xlvBoisvert 200, p. 307. Ghan üzerine cf. SWTF 9-15, P. 203a-b de de mevcut.

xlvibkz. Meulenbeld 1999-2002, IA, p. 41 Carakasaṃhitā için $(4,4,15-19)$ ve 246 ; Suśrutasaṃhitā için $(3,3,18-21)$.

xlviiSharma 1999-2001, II, P. 147.

xlviiiDossi 1998, p. 100.

xlixAnne tarafından sağlanan besin maddesi bkz ibid., p. 101.

lbkz. Meulenbeld 1999-2002, IA, p. 250. Diğer iki metin için $b k z$. İbid., p. 411 ve IIA, p. 37.

liBu terim garbhasthāna olarak da geçer. Bkz. SWTF s.v.

liiMüller 1955, p. 12.

liiiVisuddhimagga 500 (bölüm XVI, 38) çev. Nāṇamoli 2010, p. 512. T 317'de Eğer anne herhangi bir şekilde aşırı sıcak, aşırı soğuk veya aşırı katı, aşırı sıvı vb.lerini yerse çocuğun anne karnında huzursuz olacağına dikkat çekilir. bkz. Huebotter 1932, p. 20.

livPali Literatüründe bu takip eden aşama ghana dan sonraki pasākhā aşaması olarak adlandırılır. bkz. Boisvert 2000, p. 307. Sanskritçede ise bu aşama praśākhā olarak adlandırılır. S. SWTF 18, PP. 217b-218a.

lvBenim düzelttiğim metne göre benzer cümle U 410 + U 1718 + Mainz 88a + U 1664 + Mainz 87h/v/10-12' de şöyledir: ança tänlig äm[gäklig] tilgän ara yančulu ačl[g ämgäk ä]mgänür. Bu fragmanlar ayrıca DKPAM'da (Kāñcanasāra- Avadāna) da yer alır.

lviHint Tibbi Teorisi'ne göre; doğum sürecindeki rüzgarın rolü için bkz. Dossi 1998, pp. 86sq. Cf. Vasibandhu'nun çevirisi Tibetçe Mūlasarvāsrivādavinaya'dan Garbhāvakrāntisūtra ve Abhidharmakośabhāṣya içerir. Kritzer 2004, 1087-1089. Bu metin bölümler ölü doğuma odaklanmıştır. Eski Uygur Budizmi için önemlidir. Zieme/Kara 1978, II. 477-486. Soğd Maniheizmi için koşut olan Burzoes'in Kelile ve Dimme Ön sözü. Cf. Reck 2005, p. 341.

lviiKsemendra'nın Garbhāvakrāntyavadāna 'sında bu dört aşamaya dikkat çekilir. Verse 6'da: ghana, kalala, śalya ve peśî olarak verilir. Metrik nedenlerden dolayı aşamaların düzeninde arbuda'nın yerine śalya kavramı kullanılmıştır. (Hahn 1997, p. 89, dipnot 22). 
lviiiAgostini 2004, p. 67. Garbhāvakrāntinirdeśa (T 317) . Embriyonun gelişmesi ilk haftadan başlayarak 38. haftaya kadar ayrıntıları ile açıklanır. Her bir aşama embriyonun şekillenmesini sağlayan özel bir başlık altında ele alınır. Çeviri için bkz. Huebotter 1932.

lixSitātapatrādhāraṇī, karıntakı känč ed. Röhrborn/ Rona- Tas 2005, lines 216, 307.

1xBT XIII 12.28'de Biz, känčk(i)yä'yi metne (Ch/U 6016/v/9) rağmen fetüs veya embriyo nun adı olarak kullandık. Bebeğe atıf yapmak için de bununla ilişkili olarak şu dipnotu kullandık: (süt ämär känčk(i) yälär (süt emen bebekler).

lxiMaitrH XX folio 14 /r/28-29/ ve /v/9/. Bkz. düzenleme Laut 1995.

lxiiMaitrH XX folio 14 /r/28-29/ ve /v/9/. Bkz. düzenleme Laut 1995.

lxiii Toharcanın A lehçesinde embriyo için kullanılan yaygın terimdir. DKPAM ve Maitrisimit'de de aynı biçimde çevrilmiştir. bkz. DTTA, P. 31a. 